\title{
Comparison of in Vitro Young and Old Lumbar Vertebrae of Ewes Related to Bone Density and Compression Strength
}

\author{
Sahar Ahmed Abdalbary ${ }^{1} \&$ Sherif Mamdouh $\mathrm{Amr}^{2}$ \\ ${ }^{1} \mathrm{PhD}$, Department of Orthopedic Physical Therapy, Faculty of Physical Therapy, Cairo University, Cairo, Egypt \\ ${ }^{2}$ Professor at the Department of Orthopedics Surgery, Faculty of Medicine, Cairo University, Egypt \\ Correspondence: Sahar Ahmed Abdalbary, Department of Orthopedic Physical Therapy, Faculty of Physical \\ Therapy, Cairo University, Egypt. Tel: 20-1005-047-018. E-mail: saharabdalbary@gmail.com
}

Received: December 11, 2016

doi:10.5539/mas.v11n4p65

The Research has no conflict of interest.

\author{
Accepted: January 8, 2017 \\ Online Published: March 10, 2017 \\ URL: http://doi.org/10.5539/mas.v11n4p65
}

\begin{abstract}
An animal model (the ewe) was used to study the mechanical properties of lumbar vertebrae and to compare these properties with the bone mineral density. We measured the bone mineral density for lumbar vertebrae of 10 ewes for L2 \& L5 for5 young ewes mean age 2 years and 5 old ewes mean age 8 years old. Compression test was conducted on ewes lumbar vertebrae L2 \& 15 for young ewes and old ewes.

There was significance differences between both group related to bone mineral density, compressive force , and young's modulus. There was strong correlation between the mechanical properties and bone mineral density.

Bone mineral density correlated with the mechanical properties and it is not surprising that an orthopedic device used with poorly mineralized bone can have lower mechanical fixation strength than the same device with well-mineralized bone.
\end{abstract}

Keywords: bone mineral density, compression test, animal model

\section{Introduction}

Osteoporosis is a systematic disorder of the skeleton, which is characterized by loss of trabecular and cortical bone and change in the bone architecture and microstructure, leading to rapid fracture risk. Since estrogen withdrawal accelerates loss of bone mass, postmenopausal women tend to develop osteoporosis more than men at the same age (Muller et al., 2014).

Biomedical research using animal models has provided considerable direction to orthopedic developments, specifically in investigating fracture healing and bone repair.

The relative new field of tissue engineering dealing with bioactive materials, which can be suitably studied in the living organisms, depending on the using of animals as a testing ground for both experimental and clinical purposes. The evaluation of tissue-engineered orthopedic tissue relies on the functional assessment in terms of biological and biomechanical parameters ( Lie Bschner, 2004).

Aging and disease processes produce significant changes in the composition, geometry, and architecture of bone, each of which is associated with alterations in the mechanical properties of bone and the response to bone loading. Subsequently, one may find that the load required to break old aged bone is less than that required to break young bone. Mechanical characterization of the samples which is used in the research allows one to estimate the contribution and description of how this relationship may be altered due to aging and disease (Lie Bschner, 2004).

In the scientific research, the standardization of specific and reproducible mechanical tests evaluating properties of trabecular bone and compact bone have not been defined however the compression test is commonly used in the studies on non-human trabecular bone (Brearet.al,1988)or human cancellous bone (Keaveny et al.,1994).

The compression strength depends on the bone mineral content (BMC) (Keller,1994) .Hansson et al.,1980 obtained a significant correlation between BMC and the maximum compression strength $(\mathrm{r}=0.86)$. 
Ortoft et,al.!993 found that BMC measured after removal of the posterior elements was strongly correlated to the maximum load.

This study proposes a compressive test to evaluate the mechanical properties of barky ewes' lumbar vertebrae bone under standard test condition and to correlates that with non -invasive densitometric measurements of bone mineral density (BMD) was performed before the mechanical test.

The aim of this study was to determine in vitro the correlation between the mechanical properties and density measurements in lumbar vertebrae of old and young barky ewes an animal model and also to validate an experimental protocol for future characterization of human bone osteoporosis.

\section{Material and Methods}

Ethics Committee Approval for the study was obtained from the Institutional Review Board of the Department of Orthopedics Surgery of the Faculty of Medicine, Cairo University, (Approval Number, 285, Approval Date 20 March 2016).

Lumbar vertebrae from L1 to L5 were obtained from 10 clinically healthy Barky ewes , 5 of them their ages with a mean weight of $60 \mathrm{Kg}$ (group I) and the other 5 their ages 8 years old \pm 1.2 with a mean weight of $67 \mathrm{Kg}$ and at the end of their period of reproduction (group2).(Table 1)2years old $\pm_{0.4}$

Table 1. Cadaveric Demographic for both groups (Mean \pm SD)

\begin{tabular}{lll}
\hline & Young Group $(\mathrm{N}=5)$ & Old Group $(\mathrm{N}=5)$ \\
\hline Weight $/ \mathrm{Kg}$ & 60 & 67 \\
Age /year & $2 \pm 0.4$ & $8 \pm 1.2$ \\
\hline
\end{tabular}

$\mathrm{SD}=$ Standard deviation

Visual inspection of antero-posterior and lateral radiographs for each lumbar spine confirmed that each specimen was without gross anatomical defects or deformities.

The mechanical tests were performed on L2 and L5, and L1, L3, L4 have been used in other studies.

The anatomical vertebral axes (dorsal, cranial) were marked on specimens.

Vertebrae were isolated from the spine by the sectioning of the intervertebral disc. Cylinders were taken from the central part of the vertebral body with $7.3 \mathrm{~mm}$ core drill. Parallel ends were obtained with low speed blade saw (ISOMET ${ }^{\mathrm{R}}$ Low Speed Saw).

The diameter of the specimens for the compression test was $7.3 \mathrm{~mm}$ and the length was $8.7 \mathrm{~mm}$ and e was 4.7 $\mathrm{mm}$.

Pico dual energy X ray absorptiometry (PDEXA) scanning was performed for BMD value of each vertebrae were measured using PDEXA(Cosman et,al.2014). Scanning (Model PDEXA Sabre, Norland, White Plains, NY,USA) with resolution $1 \mathrm{~mm}$ by $1 \mathrm{~mm}$ and a scan area $2 \mathrm{~cm}$ by $2 \mathrm{~cm}$.

After scanning each bone specimen was independently placed into a machined aluminum platform fabricated with a cylindrical whole $7 \mathrm{~mm}$ in a diameter, to accommodate the bone core, and loaded axially using displacement control at a constant rate of $0.083 \mathrm{~mm} / \mathrm{s}$ (Wang et, al.2002)

All specimens were tested by an instron electromechanical testing system.

This system is used to test a wide range of materials.

(Instron System ID Number 3345K 2068, assembled in the USA). A cell load of 500 Newton was used, which was calibrated automatically before each testing session. Experiments were conducted in an environmental chamber $\left(37 \mathrm{c}^{\circ}\right)$ with $100 \%$ relative humidity to ensure that the material properties and water content did not alter during experimentation.

\section{Statistical Analysis}

Statistical analysis was performed with use of SPSS version 15 for windows (SPSS Inc, Chicago, IL). Data were statistically described in terms of mean and standard deviation (SD). Comparison between the young vertebrae and old vertebrae groups were performed using the unpaired student, s T test, statistically significance was defined as $\mathrm{p}$ value $<0.05$, normal distribution of data was confirmed with the Kolmogorov Simernov test of normality (Not Significant). 
The Pearson coefficient correlation $(\mathrm{R})$ was used to evaluate the correlation between different parameters.

\section{Results}

When we compared the bone mineral density (BMD) in L2 and L5 at the young ewes and old ewes there were significance difference at $\mathrm{p}=0.001$ (Table 2).

Table 2. The difference between both groups in bone mineral density (BMD) of L2 and L5 lumbar vertebrae

\begin{tabular}{llll}
\hline & Young Group(BMD)g/ $\mathrm{cm}^{-2}$ & Old Group(BMD)g $/ \mathrm{cm}^{-2}$ & P Value \\
\hline L2 Vertebrae & 0.983 & 0.469 & $0.001^{*}$ \\
L5 Vertebrae & 0.942 & 0.431 & $0.001^{*}$ \\
\hline
\end{tabular}

*Statistically significant results

The comparison between young and old ewes at the mechanical properties, which the compressive strength and young's modulus there were significance differences between both groups at $\mathrm{P}=0.001$ (Table 3 ).

Table 3. Comparison between both groups in the compression strength and young's modulus.

\begin{tabular}{llll}
\hline & Maximum compressive strength(Mpa) & Young's modulus E(Mpa) & P Value \\
\hline L2 in young group & $22.73 \pm 3$ & $1689 \pm 87$ & $0.001^{*}$ \\
L5 in young group & $22.21 \pm 2.1$ & $1650 \pm 84$ & $0.001^{*}$ \\
L2 in old group & $17.55 \pm 0.9$ & $1089 \pm 45$ & $0.001^{*}$ \\
L5 in old group & $16.34 \pm 1.7$ & $1085 \pm 34$ & $0.001^{*}$ \\
\hline
\end{tabular}

*Statistically significant results

The bone mineral density (BMD) was strongly correlated to the mechanical properties (Table 4).

Table 4. The correlation between Bone mineral Density (BMD), Maximum compression strength and young's modulus in both groups

\begin{tabular}{lll}
\hline & Young Group & Old group \\
\hline BMD L2 & $0.90^{*}$ & $0.87^{*}$ \\
BMD L5 & $0.93^{*}$ & $0.85^{*}$ \\
Maximum Compression strength & $0.79^{*}$ & $0.76^{*}$ \\
young's modulus & $0.73^{*}$ & $0.67^{*}$ \\
\hline
\end{tabular}

*Strong positive correlation coefficient at $\mathrm{p}$ value $=0.001$

\section{Discussion}

The goal of this in vitro study was to compare between young and old L2 and L5 Lumbar vertebrae related to the bone mineral density, compressive strength and young's modulus and if there is a correlation between the bone mineral density and these mechanical properties.

Patients with osteoporosis can often experience complications when they practice their daily living activities due to decreased bone mineral density and the resulting decreased compressive strength of the bone by avoiding the compressive force on the vertebrae we can avoid the complication of fracture and developing brace can decrease the compressive force on the vertebrae.

The effect of the applied strength on the bone, such as compression strength causes shortening and extension (Bankoff, 2012).

Biomechanical testing has limited application in vivo conditions because it can only be applied to examine the bones that were previously isolated from the body tissue. Numerous studies confirm that animal models are applicable to study the structure and strength of the bone in many aspects especially osteoporosis of which endurance tests are widely used in small animals (Ferretti et al., 2001; Vashesheth, 2008).

The biomechanical tests are performed relatively less often on selected irregular bone, the example of which is the compression test using lumbar vertebrae. Compression tests are performed to assess the changes in the mechanical properties of vertebrae (Muller et al., 2014). 
The age of the animals is crucial issue (sharir et al., 2008) and this appear at our study from the significance difference at the bone mineral density and the mechanical properties between the young ewes and old ewes.

The conditions before and during testing are very important, more specifically temperature and bone hydration. The most desirable surrounding temperature during the examination of biomechanical properties of specimens $\left(37 \mathrm{c}^{\circ}\right)$, testing room temperature $\left(23 \mathrm{c}^{\circ}\right)$ increases the young's modulus of bone about $2-4 \%$ compared at a test at $\left(37 \mathrm{c}^{\circ}\right)$ (Bozzini et al., 2012).

The vertebrae were slowly thawed at room temperature on day before testing and kept wrapped in the saline soaked gauze and this according to ( Kourtis et al., 2014).

The compression test is performed on the whole vertebrae causing the posterior wall of the bone spinal canal to be removed. In some cases it is eligible to perform the compression test of the vertebral body with the intact posterior process (Bozzini et al., 2012).

According to the load - displacement curve, the slope of the elastic region represents the extrinsic stiffness, which is closely linked with the mineralization of the bone(Turner and Burr 1993, Good Year and Aspden 2012, and Bozzini et al., 2012).

Furthermore, load displacement curve provide information about other biomechanical properties such as Ultimate load (force at fracture), work at fracture and ultimate displacement (Bozzini et al., 2012; Good Year \& Aspden, 2012).

Each of the aforementioned parameters reflect different properties of the bone, ultimate load reflects the general integrity of the bone structure, work to fracture is the amount of energy necessary to break the bone, and ultimate displacement is conversely related to brittleness of the bone (Turner \& Burr, 2001; Turner, 2006).

\section{Conclusion}

With a controllable in vitro bone model, surgeons placing devices in patients can more accurately determine how an orthopedic device will interact with specific patient's bone quality.

Current problems that arise from devices in osteoporotic bone include lack of stability of screws and pins as well as increased bone loss if the device fails. By testing orthopedic device or brace in bone model that simulate the stages of osteoporosis seen in patients the effectiveness and success of these can be determined. Based on the results of these tests, the devices and braces can be modified.

The study performed in vitro on an animal model we are looking to develop evaluation protocol of human vertebrae in order to predict the fracture risk in vivo.

\section{References}

Bankoff, A. D. (2012). Biomechanical characteristics of the bone. In Giovani T. (Ed): Human Musculoskeletal biomechanics. In Tech. http://doi.org/10.5772/19690

BrearKurrey, J. D., Raines, S., \& Smith. K. D. (1988). Density and temperature effects on some mechanical properties of cancellous bone .Eng Med. 17, 163-167.

Bzzini, C, Picasso E. O., Champi G. M., et al. (2012). Biomechanical properties of the mid shaft femur in middle-aged hypophysectomized rats as assessed by bending test. Endocrine, 42, 411-418, http://doi.org/10.1007/s 12020-012-9616-0

Cosman, E., Debeur, S. J., \& Le Boff, M. S., et al. (2014). Clinician,s guide to prevention and treatment of osteoporosis . Osteoporosis Int., 25, 2359-2381. http://doi.org/10.1007/s 00198-014-2794-2

Ferretti, J. L., Cointry, G. R., Cappoza, R. F., Capigliani, R., \& Chiappe, M. A. (2001). Analysis of the biomechanical effects on bone and on the muscle bone interactions in small animals models. $J$. Musculoskelet. Neuronal Interact, 1, 263-274.

Good Year, S. R., \& Aspden, R. M. (2012). Mechanical properties of bone ex vivo. Methods Mol Biol., 816, 555-571. http://doi.org/10.1007/978-1-61779-415-5_35

Hansson, T., Roos, B., \& Nachenson, A. (1980). The bone mineral content and ultimate compressive strength of lumbar vertebrae. Spine, 5, 46-55.

Keaveny, T. M., Guo, X. E., Watchel, E. F., Mahan, T. A., \& Hyes, W. C. (1994). Trabecular bone exhibits fully linear elastic behavior and yields at low strains. J. Biomechanics, 27(9), 1127-1136. http://doi.org/10.1016/0021-9290(94)900531-1

Keller, T. S. (1994). Predicting the compressive mechanical behavior of bone. J. Biomechanics, 27(9), 1159-1168. 
http://doi.org/10.1016/0021-9290(94)90056-6

Kourtis, L. C., Carter, D. R., \& Beaupre, G. S. (2014). Improving the estimate of the effective elastic modulus derived from 3 point bending tests of long bones. Ann. Biomed. Eng. 42, 1773-1780. http://doi.org/10.1007/s10439-014-1027-3

Lie Bschner, M. A. K. (2004). Biomechanical consideration of animal models is used in tissue engineering of bone. Biomaterials, 25, 1697-1714. http://doi.org/10.1016/s0142-9612(03)00515-5

Muller, R., Kampschte, M., \& Schlewtiz, G. et al. (2014). Change of mechanical vertebrae properties due to progressive osteoporosis: combined biomechanical and finite-element within a rat model. Med Biol Eng Comput, 52, 405-414. http://doi.org/10.1007/s11517-014-1140-3

Ortoft, G., Mosekelde, L., \& Hasling, C. (1993). Estimation of vertebral body strength by dual photo absorptiometry in elderly individuals: Comparison between measurements of total vertebrae and vertebral bone mineral. Bone. 14(4), 666-673. http://doi.org/10.1016/8756-3282(93) 90090-w

Sharir, A., Barak, M. M., \& Sharar, R. (2008). Whole bone mechanics and mechanical testing. Vet. J., 177, 8-17. http://doi.org/10.1016/i.tvjI. 2007.09012

Turner, C. H. (2006). Bone strength: current concepts. Ann NY Acad Sci., 1068, 429-446. http://doi.org/10.1196/annals.1346.039

Turner, C. H., \& Burr, D. B. (1993). Basic biomechanical measurements of bone: A tutorial. Bone, 14, 595-608. http://doi.org/10.1016/8756-3282(93)90081-k

Vashishth, D. (2008). Small animal bone biomechanics. Bone, 43, 794-797. http://doi.org/10.1016/jbone.2008.06013

\section{Copyrights}

Copyright for this article is retained by the author(s), with first publication rights granted to the journal.

This is an open-access article distributed under the terms and conditions of the Creative Commons Attribution license (http://creativecommons.org/licenses/by/4.0/). 